\title{
REVIEWS
}

Limnol. Oceanogr., 51(4), 2006, 1915-1924

(C) 2006, by the American Society of Limnology and Oceanography, Inc.

\section{Effects of cyanobacterial toxicity and morphology on the population growth of freshwater zooplankton: Meta-analyses of laboratory experiments}

\author{
Alan E. Wilson ${ }^{1}$ \\ Georgia Institute of Technology, School of Biology, 310 Ferst Drive, Atlanta, Georgia 30332
}

Orlando Sarnelle

Michigan State University, Fisheries and Wildlife, 13 Natural Resources Building, East Lansing, Michigan 48824

\section{Angeline R. Tillmanns}

University of Ottawa, Department of Biology, 30 Marie Curie, Ottawa, Ontario K1N 6N5 Canada

\begin{abstract}
We synthesized data from 66 published laboratory studies, representing 597 experimental comparisons, examining the effects of cyanobacterial toxicity and morphology on the population growth rate and survivorship of 17 genera (34 species) of freshwater, herbivorous zooplankton. Two meta-analyses were conducted with these data. The primary analysis compared herbivore population growth rates for grazers fed treatment diets containing cyanobacteria versus control diets comprising phytoplankton that are generally considered to be nutritious for zooplankton (chlorophytes and/or flagellates). This analysis confirmed that cyanobacteria were poor foods relative to small chlorophytes and flagellates. More importantly, filamentous cyanobacteria were found to be significantly better foods for grazers than single-celled cyanobacteria over all studies. Surprisingly, the presence or absence of commonly-measured toxic compounds (microcystins in $70 \%$ of the cases) in the diet had no overall influence on grazer population growth relative to control diets. A secondary analysis compared survival rates for grazers fed cyanobacteria versus no food. In contrast to the primary analysis, grazer survival was more negatively affected by toxic cyanobacteria than non-toxic cyanobacteria, relative to starvation. However, this difference was attributable to the effects of a single Microcystis strain, PCC7820. Thus, though some cyanobacterial strains appear to be toxic to some strains of zooplankton, the overall role of commonly-assayed cyanobacterial toxins as a determinant of food quality may be less than widely assumed. We suggest that more attention be focused on nutritional deficiencies, morphology, and the toxicity of undescribed cyanobacterial compounds as mediators of the poor food quality of cyanobacteria for zooplankton.
\end{abstract}

Interactions between bloom-forming cyanobacteria and zooplankton are central to the responses of freshwater phytoplankton assemblages to nutrient enrichment and top-down manipulation (Burns 1987; Lampert 1987; Sommer 1989). Consequently, a large body of research has been directed at understanding mechanisms by which cyanobacteria and zooplankton affect each other. This information has important implications for understanding planktonic community structure and function, as well as water quality, in lakes. For example, the filamentous

\footnotetext{
${ }^{1}$ To whom correspondence should be addressed. Present address: Cooperative Institute for Limnology and Ecosystems Research, University of Michigan, School of Natural Resources and Environment, NOAA/GLERL, 2205 Commonwealth Blvd., Ann Arbor, MI 48105-2945 (awilson@umich.edu).

\section{Acknowledgments}

We thank Allan Stewart-Oaten for invaluable assistance deriving the weighted analysis formulae and Chris Klausmeier and Kirstin Ralston-Coley for checking the derivations. Whitney Wilson was instrumental in various duties, including insightful discussions, paper retrieval, digitizing graphs, and data entry. Mark Hay, Robert Sterner, Frances Pick, Scott Findlay, and Maya Sternberg provided important suggestions about the data analysis. We also thank the following people for providing more detailed information about the studies used in this project; Michael Brett, Wayne Carmichael, Jutta Fastner, Rolland Fulton, John Gilbert, Herman Gons, Horst Krawietz, S. Nandini, Hans Paerl, Sari Repka, Koos Vijverberg, Norbert Walz, and Guntram Weithoff. Constructive suggestions from Spencer Hall, Peter Jumars, John Parker, Terry Snell, Chris Steiner, Hank Vanderploeg, and two anonymous reviewers significantly improved earlier versions of the manuscript.

Funding was graciously provided by the Environmental Protection Agency's Science to Achieve Results graduate fellowship program and the Harry and Linda Teasley endowment to Georgia Tech.
} 
morphology of certain cyanobacteria has been shown to negatively affect large cladocerans more than small cladocerans through reduced fecundity (Webster and Peters 1978; Gilbert 1990), and this mechanism may help to explain decreases in the dominance of large cladocerans with lake eutrophication (Jeppesen et al. 2000). In addition, cyanobacteria produce secondary metabolites that can cause illness and, in some cases, death of livestock and humans exposed to water with high cyanobacterial concentrations (Carmichael et al. 2001). If these metabolites are similarly toxic to copresent zooplankton, the potential for stimulation of toxin production via interactions between cyanobacteria and zooplankton could have implications for public health. Given these considerations, there is considerable value in deciphering the specific mechanisms of interaction between cyanobacteria and zooplankton.

It is well established that bloom-forming cyanobacteria are, in a general sense, of poor food quality for herbivorous zooplankton (Porter and Orcutt 1980). The following three properties of cyanobacteria have been proposed to account for this poor quality: filamentous and/or colonial morphologies, production of intracellular secondary metabolites with toxic properties, and deficiencies in essential nutrients (Porter and Orcutt 1980; Lampert 1987; DeMott 1989). Of these, morphology and toxins have attracted the most interest (Lampert 1982; Fulton and Paerl 1987; Lürling 2003). However, distinguishing between these alternative determinants of food quality is not a simple matter. Many food-quality studies have been limited to simple comparisons of zooplankton performance on diets containing or lacking cyanobacteria (Arnold 1971; Porter and Orcutt 1980), but this design does not provide clear evidence for the role of alternative determinants, given the large variety of physiological and morphological differences between cyanobacteria and other phytoplankters.

Large cyanobacterial forms, such as colonies and filaments, have been shown to mechanically interfere with zooplankton grazing by reducing ingestion of food particles (Webster and Peters 1978; Lynch 1980). An unequivocal test of the role of morphology would involve comparing the performance of zooplankton on diets consisting of cyanobacteria from the same strain but with contrasting morphologies. Such tests have been performed in relatively few studies in which a colonial or filamentous species has been disrupted into single cells or small clusters of cells via shaking or sonication. Some studies show that grazers perform better on diets composed of larger forms of cyanobacteria (Chan et al. 2004), whereas other studies show that smaller forms of cyanobacteria are better food for grazers (Hartmann 1985). These conflicting observations suggest that other factors, such as intracellular toxins and nutrient deficiencies, may interact with cyanobacterial morphology and/or grazer size in affecting zooplankton performance (Lampert 1987).

Unequivocal tests of the role of secondary metabolites are more difficult in practice and consequently rarer still. Cyanobacterial toxins have been hypothesized to be important determinants of the poor quality of cyanobacterial diets, but most studies have relied on additions of dissolved cyanobacterial extracts or purified toxins to zooplankton media (DeMott et al. 1991; Jungmann 1992), comparisons between a cyanobacterium and a starvation control (Lampert 1981), comparisons between a nutritious alga and a cyanobacterium (Lampert 1981), or comparisons between two strains of the same cyanobacterium species that differ in their ability to produce a well-studied toxin (Smith and Gilbert 1995). In general, these types of comparisons do not provide unequivocal tests of the specific role of cyanobacterial toxins in driving poor zooplankton performance. In the examples specified above, the treatment diets compared may have differed in many ways other than in the presence of a particular toxin, such as nutrient content, size, and morphology. Studies that use a starvation control are limited to comparisons of survival rates and, as a result, do not fully address effects on population growth rate. In addition, tests of the effects of dissolved toxins do not mimic the typical route of exposure for freshwater grazers (via feeding) and have involved toxin exposure levels that are orders of magnitude higher than concentrations typically observed in freshwater lakes (Chorus and Bartram 1999). Recent studies (Rohrlack et al. 1999; Kaebernick et al. 2001; Lürling 2003) comparing cyanobacteria from the same strain that have toxic, wild-type genotypes (which contain several microcystin variants), or nontoxic, mutant genotypes (which are unable to synthesize microcystins) have so far provided less than definitive support for the importance of the most commonly studied class of cyanobacterial toxin, microcystin, as a driver of poor zooplankton performance. For example, Lürling (2003) reported similar population growth rates for grazers that were fed a toxic, wild-type strain of Microcystis and grazers that were fed the nontoxic, mutant strain derived from the toxic, wild-type Microcystis strain.

In lieu of many direct tests of the effects of cyanobacterial morphology and toxicity on zooplankton performance, we conducted a meta-analysis of the dietary effects of cyanobacteria on zooplankton population growth rates, to quantitatively synthesize the current state of knowledge. In this analysis, we compared population growth rates for zooplankton fed treatment foods containing cyanobacteria with those for zooplankton fed control foods comprising chlorophytes and/or flagellates. We also recognized that some experiments address the issue of cyanobacterial toxicity in a way (e.g., via survivorship studies) that precludes them from being included in this meta-analysis. For these studies, we conducted a supplementary meta-analysis to summarize experiments in which the survival rate for grazers fed toxic or nontoxic cyanobacteria was compared with that for a control group that received no food. Comparison of a group receiving a cyanobacterial diet with a group that is undergoing starvation is a long-standing approach to the assessment of dietary toxicity (Lampert 1981), because it is assumed that grazers will die sooner if they receive toxic food than if they receive no food. Such an experimental design might be open to alternative interpretation if grazers reduce their grazing effort in the absence of food (Plath 1998) and thus have higher survival when starved than when in the presence of nutritionally deficient cyanobacteria. 
Given that a wide variety of cyanobacterial taxa with different morphologies and toxicological characteristics have been used in a large number of experiments, meta-analysis provides a powerful means of quantitatively synthesizing this literature (Osenberg et al. 1999) and indirectly assessing the role of these alternative determinants of food quality. We hypothesized that, if morphology and/or toxin production are, in general, important determinants of the poor food quality of cyanobacteria, obvious differences in zooplankton performance should be apparent across these categories in the literature. Too few studies provided detailed information about nutritional composition to permit inclusion of nutritional inadequacy as a determinant of food quality in our analyses. We chose to focus on the population growth rate $(r)$ in assessing zooplankton performance, despite a plethora of performance measures that are cited in the literature, because population growth rate integrates many alternative measures (e.g., feeding, assimilation, somatic growth, survival, and reproduction), determines evolutionary fitness, and provides the most direct link to a major goal of much of this research, which is to understand zooplankton population and community dynamics as they are affected by cyanobacteria.

\section{Methods}

We searched the literature for experimental studies of the effect of cyanobacteria on zooplankton performance using Web of Science (from 1945 to 2004), Aquatic Sciences and Fisheries Abstracts (from 1971 to 2004), the reference lists of collected articles, and suggestions by scientists familiar with these types of studies. We included all comparisons that provided data on, or from which could be calculated, population growth rates for freshwater zooplankton fed a control diet (i.e., small chlorophyte and/or flagellated algae) versus rates for those fed a diet containing cyanobacteria (the "treatment" diet) and population growth rates for freshwater zooplankton fed a treatment diet containing toxic or nontoxic cyanobacteria versus rates for those fed no food (the "starvation" diet).

The primary analysis contrasted growth rates for herbivore populations receiving treatment diets with those for herbivore populations receiving control diets, as this was our main interest and many studies used this design. No studies were found that measured population growth rate for copepods fed cyanobacteria-containing foods and a control food; thus, only cladocerans and rotifers were included in the primary analysis. The 43 articles included in the primary meta-analysis comprised 358 experimental comparisons (Web appendix 1, Tables A1 and A3; available at: http:// www.aslo.org/lo/toc/vol_51/issue_4/1915al.pdf) across $\geq 2$ dietary treatments, including 19 cladoceran and 8 rotifer species from 8 and 5 genera, respectively (Web appendix 1, Table A3). Twenty-two comparisons from six studies were excluded from the data set (Web appendix 1, Table A4) because treatment $r$ estimates could not be calculated or because control $r$ estimates were near or $<0$, which cannot be accommodated by our metric of effect size.

In most cases (99\%), zooplankton population growth rates for grazers fed control foods were reported in the articles included in the primary analysis. In the few cases in which control $r$ values were not reported (Lundstedt and Brett 1991; Gilbert 1994), we calculated $r$ from initial and final population densities $\left(r=\frac{\ln \text { density }_{t+1}-\ln \text { density }_{t}}{\text { time }}\right)$. Most population growth rate estimates $(90 \%)$ for grazers fed treatment foods also came directly from the studies. However a few studies did not provide estimates of $r$ (Web appendix 1, Fig. A1), presumably because of a lack of reproduction or because all of the experimental animals died during the assays. We did not want to exclude these studies, because they provided worst-case scenarios (i.e., large negative effects of cyanobacteria) for experimental comparisons, so we estimated $r$ for these studies from a lack of reproduction but no mortality $(r=0 ; n=4)$ and survivorship curves $(n=33)$. For studies in which all grazers died before the end of the experiment, we used a population size of 1 on the day the last grazer died to calculate $r$.

We included all comparisons regardless of whether estimates of among-replicate variance were provided and conducted an unweighted meta-analysis, to avoid biasing the data set. Use of data-exclusion criteria that are not specifically tied to the data's relevance to the question or that relate only to study "quality" can lead to spurious conclusions (Englund et al. 1999). However, given that variance-weighted estimates enable more-powerful statistical tests, we also extracted among-replicate variances, when available, for use in a parallel set of variance-weighted meta-analyses. We compared the two sets of analyses to assess the robustness of the results (Englund et al. 1999).

Additional information from each study was recorded to enable categorization of the data by cyanobacterial morphology (single-celled, colonial, or filamentous), cyanobacterial toxicity (nontoxic, toxic, or not determined), zooplankton type (cladoceran or rotifer), adult zooplankton length (actual lengths were provided in most studies; for the remaining studies, estimates were collected from the literature), control food type, carbon concentration of control and treatment foods (carbon concentrations were provided in many studies; for the remaining studies, estimates were determined by calculating biovolume from the cell density and cell dimensions [actual measurements were provided in most studies; for the remaining studies, estimates were collected from the literature] and assuming a specific gravity of 1 , a ratio of dry mass to wet mass of 0.10 , and a carbon content of dry biomass of $50 \%$ (Riemann et al. 1989)), and percentage of cyanobacterial carbon in treatment foods.

The classification of a cyanobacterium as toxic or nontoxic is central to our analysis but is not straightforward. In vitro assays (e.g., ELISA, HPLC, and LC/MS) for chemically described secondary metabolites with an established toxicity toward some organism(s) may miss inhibitory compounds that have yet to be described. Reliance on such assays for classification might result in some toxic cyanobacteria being misclassified as nontoxic. Alternatively, bioassays that use terrestrial animals or aquatic animals with no previous evolutionary history of exposure to the compound may result in a compound being characterized 
as toxic when it is not inhibitory to animals that coexist with the compound in nature. In this case, nontoxic strains would be misclassified as toxic. These ambiguities cannot be resolved by any classification scheme. Indeed, one of the main motivations for this work was to assess whether wellknown compounds are indeed inhibitory, in a general sense, to zooplankton population growth when they are part of the diet. Consequently, we chose to focus on the following specific question: does the presence or absence of previously described secondary metabolites with toxic effects on some organism have an influence on the population growth rate of zooplankton, in general?

Cyanobacteria were considered toxic if they tested positive via in vitro analysis for known toxins (anatoxin, cylindrospermopsin, deazaadenosine, glucopyranoside, microcystin, microviridin, and paralytic shellfish toxin). Toxin concentrations are known to vary within and among cyanobacterial strains under different environmental conditions and physiological states (Lee et al. 2000). However, these data were not routinely provided and consequently could not be included in our analysis. Nontoxic cyanobacteria were those that either tested negative for known toxins via in vitro analysis or, in one case (Arnold 1971), were considered to be nontoxic because the strains were members of genera (i.e., Gleocapsa, Merismopedia, and Synechocystis) that, to our knowledge, have never been shown to produce toxins. Cases in which potentially toxic genera of cyanobacteria (e.g., Microcystis, Anabaena, and Oscillatorial Planktothrix) were not chemically analyzed for toxins were designated as "not determined." We contacted authors to obtain information about the toxicity of cyanobacterial strains when this information was not included in their article. This inquiry netted an additional 45 comparisons (total $n=265$ ) that could be classified as toxic or nontoxic in the primary analysis.

For the primary analysis, the effect of cyanobacteria on zooplankton population growth relative to control foods was calculated for each experimental comparison $(n=358)$ as follows:

$$
\text { Unweighted effect size }=\frac{r_{t}-r_{c}}{r_{c}}
$$

where $r_{t}$ is the population growth rate on the cyanobacterial (treatment) diet and $r_{c}$ is the population growth rate on the control diet (e.g., small chlorophyte and/or flagellate). This metric was chosen to standardize effect sizes by maximum population growth rate (i.e., growth rate on control foods) across taxa with varying growth rates and to center the results about zero to facilitate interpretation. An effect size of zero indicates that growth rates on the two diets were similar. Negative effect sizes indicate that growth rates were lower during receipt of the cyanobacterial diet than growth during receipt of the control diet. Effect sizes less than -1 indicate that population growth during receipt of the cyanobacteria diet $\left(r_{t}\right)$ was negative, because $r_{c}$ was always greater than zero. Weighted effect sizes $(n=285)$ were calculated as follows:

$$
\text { Weighted effect size }=\frac{r_{t}}{r_{c}}+\frac{r_{t} \times \operatorname{var} r_{c}}{r_{c}^{3}}-1
$$

Variances for these weighted effects sizes were calculated as follows:

$$
\text { Weighted variance }=\frac{\operatorname{var} r_{t}}{r_{c}^{2}}+\frac{\operatorname{var} r_{c}}{r_{c}^{4}}
$$

In the secondary meta-analysis, 23 articles provided data $(n=239)$ for cladocerans (5 genera and 12 species), copepods ( 3 genera and 3 species), a rotifer (1 genus and 1 species), and a fairy shrimp (1 genus and 1 species) fed nontoxic $(n=27)$ or toxic $(n=212)$ cyanobacteria or no food (Web appendix 1, Tables A2 and A3). Data for one study (Arnold 1971) were not included because starved grazers exhibited positive population growth, suggesting a methodological problem in the starvation treatment (Web appendix 1, Table A4). In this analysis, estimates of $r$ (measured as survival rate) were collected directly or calculated from initial and final densities. For studies in which all grazers died before the end of the experiment, we used a population size of 1 on the day the last grazer died to calculate $r$.

A different effect size metric was needed for the secondary analysis, because the data in most of these studies were limited to survivorship estimates over time, which result in population growth rate estimates $\leq 0$. Because estimates of $r \leq 0$ cannot be accommodated by the effect size metric noted above $\left(\frac{r_{t}-r_{c}}{r_{c}}\right)$, we calculated effect sizes for grazers fed cyanobacteria ${ }^{{ }_{c}}$-containing foods (treatment) with effect sizes for starved grazers as follows:

$$
\text { Difference effect size day }{ }^{-1}=r_{t}-r_{s}
$$

where $r_{t}$ is the survival rate during receipt of the cyanobacterial (treatment) diet, and $r_{s}$ is the survival rate for starved grazers. An effect size of zero indicates that survival rates associated with the two diets were similar. Negative effect sizes indicate that survival rates during receipt of the cyanobacterial diet were lower than those for the starved diet (i.e., that zooplankton survival was inhibited by cyanobacteria relative to starvation).

Population growth rates for grazers fed control or treatment foods were compared using a paired Student's $t$-test. Analysis of variance (ANOVA) and its weighted analog (MetaWin, version 2.1) were used to test for differences in effect size among categorical means and to identify significant interactions, and Tukey's multiple comparison tests was used when $>2$ means were being compared. We used random-effects models for all categorical, weighted analyses because we did not assume a single, true effect size across the disparate studies, which is done for fixed-effects models. Linear regression was used to examine relationships between effect sizes and grazer size or the percentage of cyanobacteria in treatment foods. A general linear model (GLM) was used to test for interactions (i.e., homogeneity of slopes test) between grazer size and cyanobacterial morphology or toxicity. Analysis of covariance (ANCOVA) was used to test for effects of cyanobacterial toxicity and morphology after accounting for variation attributable to continuous variables (i.e., grazer size and percentage of cyanobacteria in the 

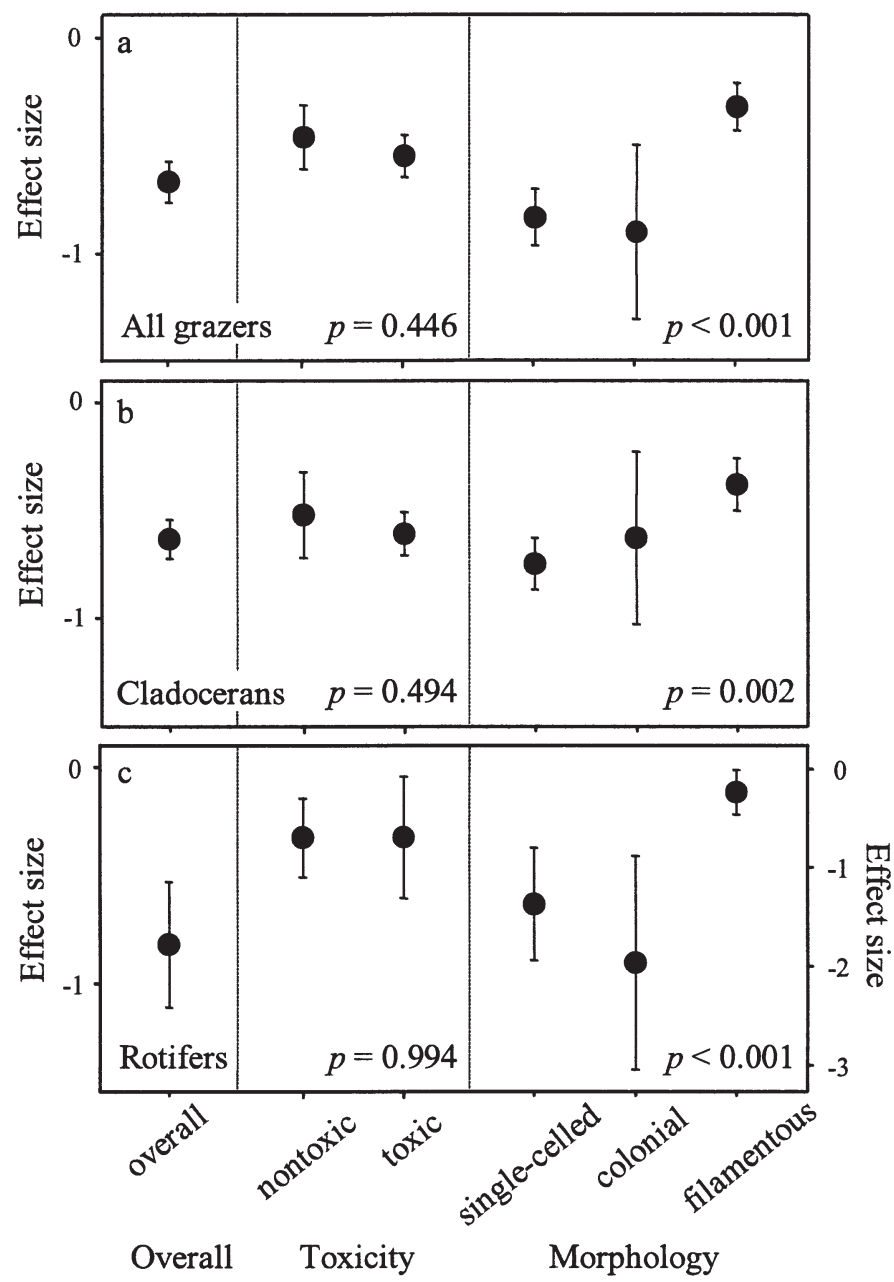

Fig. 1. Effect size averages and 95\% confidence intervals for the unweighted data set from the primary meta-analysis comparing $r$ for (a) all grazers, (b) cladocerans only, and (c) rotifers only fed control foods composed of chlorophytes and/or flagellates and treatment foods containing cyanobacteria. Note scale change for cyanobacterial morphology mean effect sizes for rotifers. Sample sizes are presented in Table 1.

treatment diet). ANCOVA was used only if slopes (e.g., effect size vs. grazer length or the percentage of cyanobacteria in the treatment diet) were not significantly different at a $p$ value of $<0.05$. Unweighted and weighted analyses were performed with Systat, version 9.01 (SPSS 1998), and MetaWin, version 2.1 (Rosenberg et al. 2002), respectively. The rejection criterion was set a priori at an $\alpha$ level of $<0.05$.

\section{Results}

As expected, zooplankton population growth rates were much lower ( $p<0.001$, by the paired $t$-test) for diets containing cyanobacteria (mean $[ \pm \mathrm{SE}], 0.191 \pm 0.024$ ), compared with control diets (mean $[ \pm \mathrm{SE}], 0.479 \pm 0.025$ ), and as a result, the mean effect sizes averaged over all studies were negative (mean effect sizes were significantly $<0$; $p<$ 0.001 , by the $t$ test) (Fig. 1; Table 1). The magnitude of growth inhibition by cyanobacteria also increased as the percentage of cyanobacteria in the treatment diet increased $(p<0.001)$ (Fig. 2a; Table 2). Significant inhibition of zooplankton population growth was evident for all three morphological types (effect sizes for all morphological types were significantly $<0 ; p<0.001$, by one sample $t$ tests), but single-celled and colonial forms inhibited growth more than did filamentous forms overall (Fig. 1; Table 1). Surprisingly, there was no statistically significant difference in effect size ( $p=0.446$ ) between populations receiving toxic cyanobacteria and populations receiving nontoxic cyanobacteria, despite large sample sizes (total $n=265$ ) and low residual error (Fig. 1; Table 1).

We also examined interactions between grazer length, morphology, and toxicity and cyanobacterial morphology and toxicity. Our analysis of the interaction between morphology and toxicity was limited by the lack of nontoxic colonial species in the data set, and so it only includes a comparison of filamentous and single-celled morphologies. For all grazers, no significant interactions were found between cyanobacterial toxicity $(p=0.993)$ and grazer length $(p=0.001)$ (toxicity $\times$ grazer length interaction, $p=0.248$ ) or cyanobacterial morphology ( $p<$ $0.001)$ and toxicity $(p=0.020)$ (morphology $\times$ toxicity interaction, $p=0.313$ ). However, a significant interaction was found between cyanobacterial morphology $(p<0.001)$ and grazer length $(p=0.035)$ (morphology $\times$ grazer length interaction, $p=0.004)$, Moreover, the effect of cyanobacteria across grazer lengths varied among cyanobacteria types (Table 2). Effect sizes were negatively related to increasing grazer length for filamentous, nontoxic, and toxic cyanobacteria $(p \leq 0.019)$ (Table 2$)$ and positively related to increasing grazer length for colonial cyanobacteria $(p=0.036)$ (Table 2), but no relationship was found between grazer length and single-celled cyanobacteria ( $p=$ 0.667) (Table 2).

There was no statistically significant difference in inhibition between cladocerans and rotifers over all studies $(p=0.110)$ (Fig. 1), which is consistent with the lack of a significant relationship between effect size and grazer length across all studies $(p=0.428)$ (Fig. 2b; Table 2). Moreover, neither type of grazer responded differently to toxic and nontoxic cyanobacteria $(p \geq 0.49)$ (Fig. 1; Table 1). However, when analyzed separately, cladocerans and rotifers did respond somewhat differently to the distinct cyanobacterial morphologies $(p \leq 0.002)$ (Fig. 1; Table 1). Both grazer groups were inhibited more by singlecelled cyanobacteria than by filamentous cyanobacteria, but rotifers were more negatively affected by colonial and single-celled cyanobacteria than were cladocerans $(p \leq$ 0.005) (Fig. 1). Of interest, rotifer performance during receipt of filamentous cyanobacteria was similar to their performance during receipt of control foods (Fig. 1; Table 1). However, the mean effect size was negative and nearly significantly $<0$ (one sample $t$-test of mean $=0 ; p=$ 0.056 ). Unweighted and weighted analyses provided similar outcomes in most of the cases described above (Tables 1 and 2).

Given the unexpected and potentially controversial finding that cyanobacterial toxicity had little influence on 
Table 1. Results for the primary meta-analysis comparing $r$ for grazers fed control foods comprised of chlorophytes and/or flagellates and treatment foods containing cyanobacteria.*

\begin{tabular}{|c|c|c|c|c|c|c|c|c|c|}
\hline Comparisons & Group & $\begin{array}{c}\text { Un- } \\
\text { weighted } \\
n\end{array}$ & $\begin{array}{c}\text { Unweighted } \\
\text { mean effect } \\
\text { size }\end{array}$ & $\begin{array}{l}\text { Unweighted } \\
95 \% \mathrm{CI} \dagger\end{array}$ & $\begin{array}{c}\text { Un- } \\
\text { weighted } \\
p \text { valuef }\end{array}$ & $\begin{array}{l}\text { Weighted } \\
n\end{array}$ & $\begin{array}{l}\text { Weighted } \\
\text { mean effect } \\
\text { size }\end{array}$ & Weighted $95 \% \mathrm{CI} \dagger$ & $\begin{array}{l}\text { Weighted } \\
p \text { valuet }\end{array}$ \\
\hline Overall effect & & 358 & -0.673 & -0.768 to -0.579 & & 285 & -0.412 & -0.450 to -0.374 & \\
\hline Toxicity & $\begin{array}{l}\text { nontoxic } \\
\text { toxic }\end{array}$ & $\begin{array}{r}45 \\
220\end{array}$ & $\begin{array}{l}-0.457 \\
-0.544\end{array}$ & $\begin{array}{l}-0.606 \text { to }-0.308 \\
-0.642 \text { to }-0.447\end{array}$ & 0.446 & $\begin{array}{r}34 \\
193\end{array}$ & $\begin{array}{l}-0.368 \\
-0.320\end{array}$ & $\begin{array}{l}-0.463 \text { to }-0.272 \\
-0.360 \text { to }-0.281\end{array}$ & 0.355 \\
\hline Morphology & $\begin{array}{l}\text { single-celled } \\
\text { colonial } \\
\text { filamentous }\end{array}$ & $\begin{array}{r}199 \\
38 \\
119\end{array}$ & $\begin{array}{l}-0.836^{\mathrm{a}} \\
-0.905^{\mathrm{a}} \\
-0.325^{\mathrm{b}}\end{array}$ & $\begin{array}{l}-0.967 \text { to }-0.704 \\
-1.309 \text { to }-0.501 \\
-0.436 \text { to }-0.215\end{array}$ & 0.000 & $\begin{array}{r}155 \\
28 \\
101\end{array}$ & $\begin{array}{l}-0.612 \\
-0.568 \\
-0.252\end{array}$ & $\begin{array}{l}-0.669 \text { to }-0.556 \\
-0.735 \text { to }-0.400 \\
-0.298 \text { to }-0.207\end{array}$ & 0.001 \\
\hline Grazer type & $\begin{array}{l}\text { cladocerans } \\
\text { rotifers }\end{array}$ & $\begin{array}{r}280 \\
78\end{array}$ & $\begin{array}{l}-0.633 \\
-0.819\end{array}$ & $\begin{array}{l}-0.723 \text { to }-0.542 \\
-1.109 \text { to }-0.529\end{array}$ & 0.110 & $\begin{array}{r}220 \\
65\end{array}$ & $\begin{array}{l}-0.386 \\
-0.473\end{array}$ & $\begin{array}{l}-0.432 \text { to }-0.340 \\
-0.542 \text { to }-0.403\end{array}$ & 0.038 \\
\hline $\begin{array}{l}\text { Cladocerans } \\
\text { only }\end{array}$ & & & & & & & & & \\
\hline Toxicity & $\begin{array}{l}\text { nontoxic } \\
\text { toxic }\end{array}$ & $\begin{array}{r}32 \\
177\end{array}$ & $\begin{array}{l}-0.513 \\
-0.600\end{array}$ & $\begin{array}{l}-0.712 \text { to }-0.315 \\
-0.700 \text { to }-0.500\end{array}$ & 0.494 & $\begin{array}{r}23 \\
152\end{array}$ & $\begin{array}{l}-0.401 \\
-0.335\end{array}$ & $\begin{array}{l}-0.517 \text { to }-0.285 \\
-0.382 \text { to }-0.288\end{array}$ & 0.280 \\
\hline Morphology & $\begin{array}{l}\text { single-celled } \\
\text { colonial } \\
\text { filamentous }\end{array}$ & $\begin{array}{r}170 \\
30 \\
78\end{array}$ & $\begin{array}{l}-0.747^{\mathrm{a}} \\
-0.627^{\mathrm{a}, \mathrm{b}} \\
-0.380^{\mathrm{b}}\end{array}$ & $\begin{array}{l}-0.866 \text { to }-0.629 \\
-1.026 \text { to }-0.228 \\
-0.502 \text { to }-0.258\end{array}$ & 0.002 & $\begin{array}{r}130 \\
24 \\
66\end{array}$ & $\begin{array}{l}-0.599 \\
-0.372 \\
-0.195\end{array}$ & $\begin{array}{l}-0.658 \text { to }-0.541 \\
-0.560 \text { to }-0.184 \\
-0.241 \text { to }-0.150\end{array}$ & 0.000 \\
\hline Rotifers only & & & & & & & & & \\
\hline Toxicity & $\begin{array}{l}\text { nontoxic } \\
\text { toxic }\end{array}$ & $\begin{array}{l}13 \\
43\end{array}$ & $\begin{array}{l}-0.318 \\
-0.316\end{array}$ & $\begin{array}{l}-0.500 \text { to }-0.136 \\
-0.598 \text { to }-0.033\end{array}$ & 0.994 & $\begin{array}{l}11 \\
41\end{array}$ & $\begin{array}{l}-0.292 \\
-0.286\end{array}$ & $\begin{array}{l}-0.490 \text { to }-0.093 \\
-0.366 \text { to }-0.205\end{array}$ & 0.951 \\
\hline Morphology & $\begin{array}{l}\text { single-celled } \\
\text { colonial } \\
\text { filamentous }\end{array}$ & $\begin{array}{r}29 \\
8 \\
41\end{array}$ & $\begin{array}{l}-1.354^{\mathrm{a}} \\
-1.947^{\mathrm{a}} \\
-0.221^{\mathrm{b}}\end{array}$ & $\begin{array}{l}-1.921 \text { to }-0.786 \\
-3.026 \text { to }-0.868 \\
-0.447 \text { to } 0.006\end{array}$ & 0.000 & $\begin{array}{r}25 \\
4 \\
36\end{array}$ & $\begin{array}{l}-0.683 \\
-1.420 \\
-0.336\end{array}$ & $\begin{array}{l}-0.845 \text { to }-0.522 \\
-2.086 \text { to }-0.755 \\
-0.459 \text { to }-0.213\end{array}$ & 0.000 \\
\hline
\end{tabular}

* Differences in letter (a,b) indicate significant differences as detected by Tukey's multiple comparison tests.

$\dagger$ Confidence intervals (CIs) containing zero signify that the treatment and control foods affected grazers similarly.

$\$ p$ values relate to specific effect size comparisons (e.g., cladocerans versus rotifers, nontoxic versus toxic cyanobacteria).

mean effect size in studies comparing a cyanobacterial diet with a control diet, we analyzed the primary data set more intensively to examine the robustness of this specific result. First, we examined whether there was an interaction between the concentration of cyanobacteria in treatment foods and the presence or absence of toxicity. There was no interaction between cyanobacterial concentration and toxicity $(p=0.477)$ and no statistically significant effect of toxicity after accounting for variation in cyanobacterial concentration (for percentage of cyanobacteria in the diet, $p<0.001$, by ANCOVA; for toxicity, $p=0.378$, by ANCOVA). Second, we restricted the data set to studies in which the treatment diet was made up of $100 \%$ cyanobacteria, given that these treatments showed the strongest negative effects on population growth (Fig. 2a). Again, effect sizes between toxic and nontoxic cyanobacteria diets were not significantly different for all grazers $(p=0.354)$, nor for cladocerans $(p=0.527)$ and rotifers $(p=0.355)$ analyzed separately. Finally, we examined the influence of variation in the control diet on effect size. Zooplankton exhibited greater population growth on control diets made up of Cryptomonas, Nannochloris, or Euglena organisms relative to other species (overall, $p<0.001$ ) (Fig. 2a; Web appendix 1). We analyzed the data after subdividing effect sizes into two categories on the basis of the type of control food that was used (Cryptomonas, Euglena, and Nannochloris organisms were considered to be better food, and Chlorella, Scenedesmus and other genera were considered to be poorer food). Neither data subset revealed statistically significant differences in mean effect size for grazers fed toxic or nontoxic cyanobacteria ( $p \geq 0.473)$.
In direct contrast to the lack of influence of toxicity in the analysis of experiments in which control foods were used (Fig. 1; Table 1), the secondary analysis of experiments that used a starvation treatment revealed that receipt of toxic cyanobacteria (mean $[ \pm \mathrm{SE}],-0.237 \mathrm{day}^{-1} \pm 0.027$ day $^{-1} ; n=212$ ) resulted in greater zooplankton growth than did receipt of nontoxic cyanobacteria (mean $[ \pm \mathrm{SE}$ ], 0.093 day $^{-1} \pm 0.030$ day $^{-1} ; n=27 ; p<0.001$ ) (Fig. 3). Grazers fed toxic cyanobacteria exhibited significantly lower survival rates than starved animals (one sample $t$-test of mean $=0 ; p$ $<0.001$ ), whereas grazers fed nontoxic cyanobacteria exhibited significantly higher survival rates than starved animals (one sample $t$-test of mean $=0 ; p=0.005$ ). This data set was heavily biased towards the use of Microcystis species (93\% of the cyanobacterial treatment food types in the secondary analysis), and more specifically, the microcystincontaining strain M. aeruginosa PCC7820 (37\% of the toxic treatment foods in the secondary meta-analysis, compared with only $21 \%$ of the toxic treatment foods in the larger, primary analysis). Repeated use of the same species or genotype is an obvious source of nonindependence in metaanalysis (Gurevitch and Hedges 1999) and may limit the domain of relevance of our synthesis in much the same way that pseudoreplication affects the interpretation of an individual experiment (Hurlbert 1984). It is possible that the significant influence of toxicity in the secondary analysis is driven solely by the effect of this single genotype of $M$. aeruginosa. To address this possibility, we examined the influence of toxicity in experiments that used PCC7820 and experiments that used other toxic strains (Fig. 3). This analysis revealed that the influence of toxicity on zooplank- 


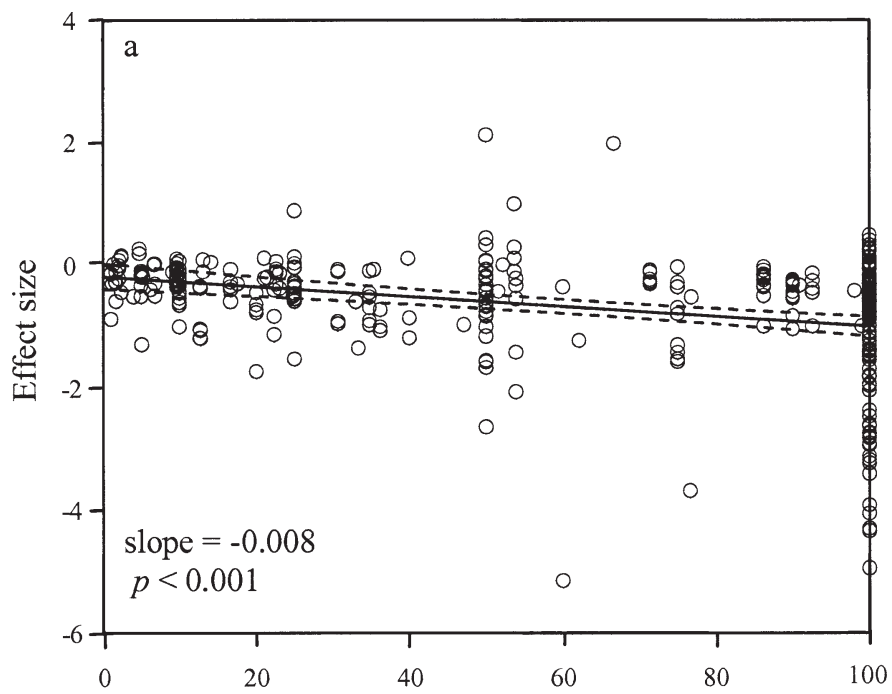

Percent cyanobacteria in treatment food

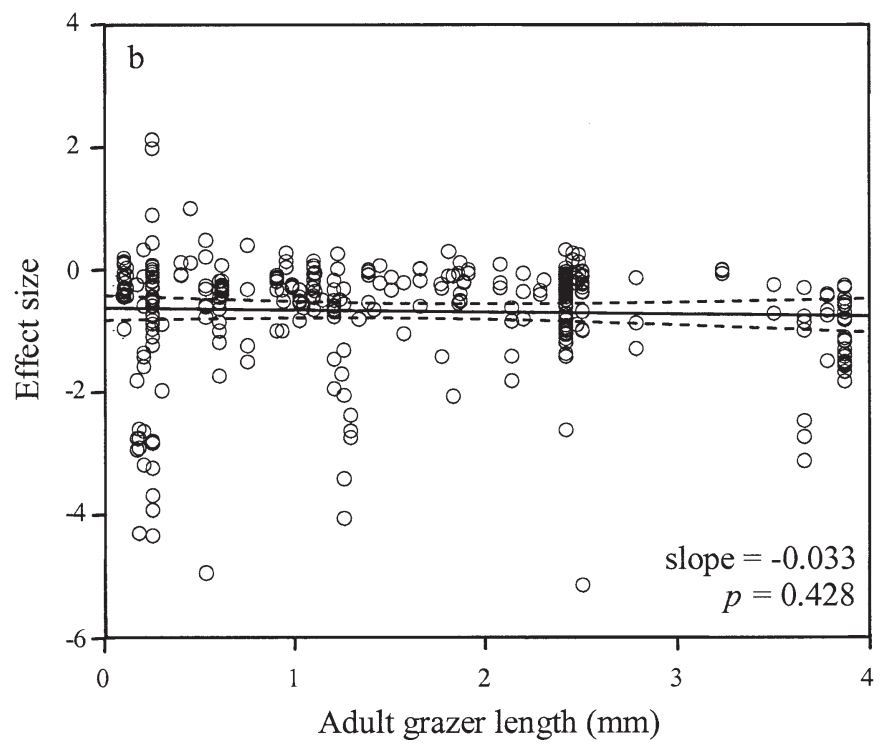

Fig. 2. Relationships between unweighted effect size and (a) percentage of cyanobacteria in treatment foods or (b) adult grazer length $(\mathrm{mm})$ for the primary data set comparing $r$ for grazers fed control foods comprised of chlorophytes and/or flagellates and treatment foods containing cyanobacteria. Solid lines are best-fit lines. Dashed lines are 95\% confidence bands. Transformation to remove heteroscedasticity did not change the results of the regression appreciably.

ton survival rates is statistically significant, even in the absence of PCC7820 (results for nontoxic diets are presented above; the mean value $[ \pm \mathrm{SE}]$ for all other toxic strains besides PCC 7820 $[n=133]$ was -0.184 day $^{-1} \pm 0.031$ day $^{-1}$ $[p<0.001]$ for all other toxic strains vs. nontoxic strains; the mean value for PCC7820 strains only $[n=79]$ was -0.326 $\mathrm{day}^{-1} \pm 0.051 \mathrm{day}^{-1}[p<0.001]$ for PCC7820 strains vs. nontoxic strains), and also that the magnitude of the difference in effect sizes between comparisons of toxic and nontoxic cyanobacteria is much (44\%) less for all other strains than it is for PCC7820 (Fig. 3).

\section{Discussion}

Using two meta-analyses of published data, we confirmed that cyanobacteria are generally poor food for freshwater grazers, compared with small chlorophytes and/ or flagellates, a generalization that is widely presumed to be true (Porter and Orcutt 1980; Sommer 1989; Gilbert 1990). The very low $p$ values associated with the general effect of cyanobacteria and for the effect of increasing concentrations of cyanobacteria $(p<0.001)$ indicate that our analysis was relatively powerful, as would be expected, given the generally large samples sizes (Tables 1 and 2; Web appendix 1, Tables A1, A2, and A3). Despite these large sample sizes, however, we did not find an overall statistical difference in population growth inhibition between toxic and nontoxic cyanobacteria (as defined in our analysis), a generalization that is also widely presumed to be true. We also found that cladocerans and rotifers were affected differently by the distinct cyanobacterial morphologies, a finding that has not been widely recognized before (Gilbert 1990; Nandini and Rao 1998).

In general, cladocerans and rotifers responded similarly to cyanobacteria regardless of toxin absence or presence, compared with control foods. These findings were somewhat unexpected, given that cladocerans and rotifers use different chemosensory and mechanosensory structures to locate and ingest prey (Larsson and Dodson 1993; Snell 1998). However, we did find statistically significant differences between the two grazer groups in their responses to different cyanobacterial morphologies (Fig. 1). Cladocerans and rotifers both grew best on filamentous forms, but rotifers were more inhibited by single-celled and colonial cyanobacteria, whereas cladocerans were most inhibited when fed single-celled cyanobacteria ( $p<0.05$, by Tukey's test) (Fig. 1; Table 1 ).

Across 27 species of freshwater grazers incorporated in the primary analysis (Web appendix 1, Table A3), filamentous algae were a better food source than singlecelled cyanobacteria, compared with control foods. This finding is surprising, given that filamentous cyanobacteria have been shown to mechanically interfere with herbivorefiltering appendages (Lynch 1980; Porter and McDonough 1984; Gliwicz 1990), thus reducing ingestion of food particles. We consider two explanations for the difference between the effects of filamentous and single-celled cyanobacteria. First, for phylogenetic reasons, filamentous and single-celled genera may lack different essential nutrients. For example, the filamentous cyanobacterium Anabaena has been found to be deficient in sterols (von Elert et al. 2003), whereas a strain of single-celled Synechococcus lacked essential fatty acids (von Elert and Wolffrom 2001). Alternatively, single-celled cyanobacteria may be ingested more readily than filamentous algae, because of grazer gape limitations (Gliwicz and Siedlar 1980), and these smaller prey may contain undescribed secondary metabolites that function as toxins only when consumed (Wolfe 2000).

Single-celled cyanobacteria occur in nature (e.g., Chroococcus, Dactylococcopsis, Synechococcus, and Synechocystis), but we are unaware of any naturally-occurring, toxic, 
Table 2. Linear regression output for the unweighted and weighted analyses of the primary data set comparing $r$ for grazers fed control foods comprised of chlorophytes and/or flagellates and treatment foods containing cyanobacteria.

\begin{tabular}{|c|c|c|c|c|c|c|c|}
\hline $\begin{array}{l}\text { Independent } \\
\text { variable }\end{array}$ & $\begin{array}{c}\text { Dependent } \\
\text { variable }\end{array}$ & $\begin{array}{c}\text { Unweighted } \\
n\end{array}$ & $\begin{array}{l}\text { Unweighted } \\
\text { slopes }\end{array}$ & $\begin{array}{c}\text { Unweighted } \\
p \text { value }\end{array}$ & $\begin{array}{c}\text { Weighted } \\
n\end{array}$ & $\begin{array}{l}\text { Weighted } \\
\text { slope }\end{array}$ & $\begin{array}{l}\text { Weighted } \\
p \text { value }\end{array}$ \\
\hline \multirow{8}{*}{$\begin{array}{l}\text { Percent cyanobacterial } \\
\text { carbon in treatment } \\
\text { diet }(\%)\end{array}$} & all grazers & 358 & -0.008 & 0.000 & 285 & -0.005 & 0.000 \\
\hline & cladocerans & 280 & -0.005 & 0.000 & 220 & -0.003 & 0.000 \\
\hline & rotifers & 78 & -0.020 & 0.000 & 65 & -0.013 & 0.000 \\
\hline & nontoxic & 45 & -0.008 & 0.000 & 34 & -0.011 & 0.000 \\
\hline & toxic & 220 & -0.006 & 0.000 & 193 & -0.002 & 0.000 \\
\hline & single-celled & 199 & -0.010 & 0.000 & 155 & -0.012 & 0.000 \\
\hline & colonial & 38 & -0.017 & 0.022 & 28 & -0.012 & 0.018 \\
\hline & filamentous & 119 & -0.005 & 0.000 & 102 & -0.001 & 0.034 \\
\hline \multirow[t]{6}{*}{ Grazer adult size (mm) } & all grazers & 355 & -0.033 & 0.428 & 282 & -0.036 & 0.035 \\
\hline & nontoxic & 45 & -0.151 & 0.003 & 34 & -0.139 & 0.007 \\
\hline & toxic & 217 & -0.243 & 0.000 & 190 & -0.092 & 0.000 \\
\hline & single-celled & 199 & 0.024 & 0.667 & 155 & -0.061 & 0.102 \\
\hline & colonial & 38 & 0.605 & 0.036 & 28 & 0.412 & 0.060 \\
\hline & filamentous & 116 & -0.142 & 0.019 & 99 & 0.057 & 0.002 \\
\hline
\end{tabular}

single-celled, freshwater cyanobacterial species. Given that species of Microcystis, a strictly colonial genus (Komárek 1991), constituted $62 \%$ of the treatment foods types in our primary meta-analysis, our observation that relatively few studies measured population growth for grazers fed colonial cyanobacteria is surprising. However, as near as we can ascertain, Microcystis strains from culture collections almost invariably grow as single cells, and many $(35 \%)$ of the articles in our primary meta-analysis used culture-collection strains from this genus. A total of $83 \%$ of the effect size comparisons involving Microcystis species used single-celled strains. Given the importance of morphology as a determinant of food quality (Fig. 1; Tables 1

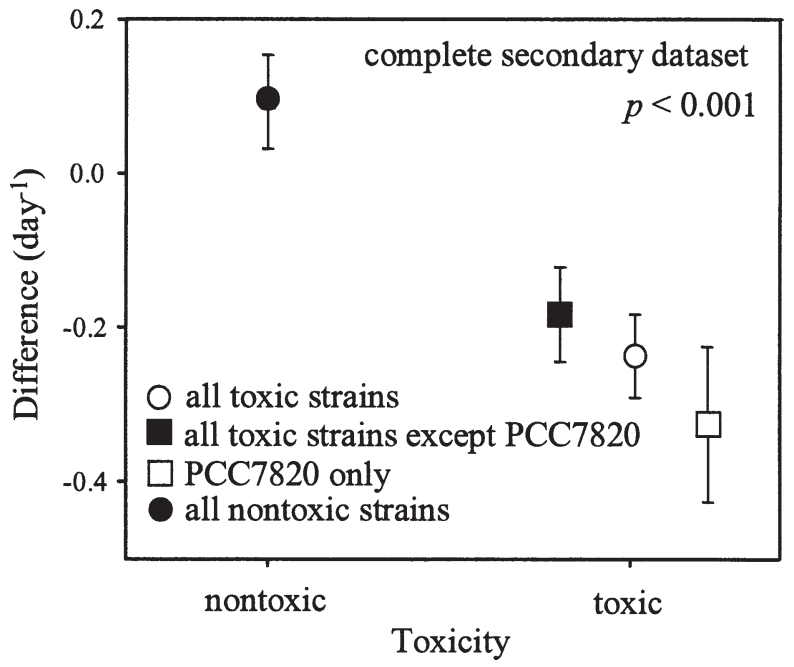

Fig. 3. Effect size differences (day ${ }^{-1}$, metric: $r_{t}-r_{s}$ where $r_{t}$ is the survival rate on the cyanobacterial (treatment) diet and $r_{s}$ is the survival rate with no food) and $95 \%$ confidence intervals for the secondary analysis. Toxic cyanobacterial data presented as all toxic strains, all toxic cyanobacteria excluding PCC7820, and only data for PCC7820. Complete secondary analysis refers to all nontoxic strains versus all toxic strains. and 2) and grazing-resistance (Sterner 1989), widespread use of single-celled strains of colonial species in studies of phytoplankton-zooplankton interactions is problematic. This problem can be overcome by using cyanobacteria that have been recently collected from the field (Nandini and Rao 1998) or remain colonial in culture (Ferrão-Filho and Azevedo 2003), whereas Microcystis can retain the colonial habit for several years (A.E. Wilson, pers. comm.).

We did not find any evidence that chemically assayed secondary metabolites, such as anatoxins and microcystins, had an overall influence on population growth rates of cladocerans and rotifers (Fig. 1), but we did find some evidence of a toxicity influence on zooplankton survival rates in the secondary analysis of experiments comparing cyanobacterial diets with starvation diets (Fig. 3). The magnitude of the latter effect, however, was greatly influenced by a single genotype of $M$. aeruginosa (PCC7820), which has been used repeatedly in published studies and has been shown to produce at least 10 different microcystin variants, including microcystin-LR, -LY, -LW, and -LF (Robillot et al. 2000). In fact, if we reduce nonindependence in the secondary data set by representing each genotype by a single observation (by averaging effects sizes within each genotype), the influence of toxicity is no longer statistically significant (the mean value $[ \pm \mathrm{SE}]$ for nontoxic diets $[n=7]$ was $0.033 \mathrm{day}^{-1} \pm 0.075 \mathrm{day}^{-1}$, and the mean value $[ \pm \mathrm{SE}]$ for toxic diets $[n=21]$ was -0.209 day $^{-1} \pm 0.080$ day $^{-1} ; p=0.109$ ). As a consequence, we are forced to conclude that, with perhaps the exception of $M$. aeruginosa genotype PCC7820, there is no strong evidence in the literature to support the generalization that the presence or absence of described cyanotoxins is an important factor driving the poor quality of cyanobacteria as food for zooplankton in general. This does not negate specific cases where zooplankton have been shown to be more negatively affected by diets containing toxic cyanobacteria than by diets containing nontoxic cyanobacteria (Rohrlack et al. 2001), but it suggests that such cases are the exception rather than the rule. 
The potential discrepancy in the influence of cyanobacterial toxicity between the population-growth analyses (Fig. 1) and survival-only analyses (Fig. 3) might be explained by the extraordinary negative effects of cyanobacteria used in the studies included in the secondary analysis (Web appendix 1, Table A2). In these studies, zooplankton fed diets containing toxic cyanobacteria perished before reproduction, which precluded the ability to calculate population growth rate. Studies incorporated in the primary analyses may have used less toxic strains of cyanobacteria or toxic strains at lower doses, thereby enabling the grazers to reproduce. Thus, the inconsistency between the primary and secondary analyses could be attributable to the effects of a small number of strains of toxic cyanobacteria (e.g., PCC7820) and so may not be a general phenomenon (Fig. 3).

Several studies suggest that alternative, undescribed secondary metabolites may be responsible for chemically mediated cyanobacterial inhibition of grazers (Jungmann 1992; Rohrlack et al. 1999). Given the results we report (Fig. 1; Tables 1 and 2), perhaps more research effort should be used to investigate these alternative compounds. In addition, new experimental techniques are needed to better clarify the role of both known and unknown chemical defenses in phytoplankton-zooplankton interactions (Caldwell et al. 2004). As one example, we caution against relying on mouse bioassays (Carmichael 1992) to classify cyanobacterial taxa or secondary metabolites as "toxic" in the ecological sense of a chemical defense against herbivores, because effects on naive vertebrates (e.g., mice) may have little relevance with respect to effects on naturally occurring invertebrates (e.g., zooplankton). Such bioassays are, of course, appropriate for identifying toxins in the context of public health (Carmichael et al. 2001). Finally, recent studies indicate that grazers can adapt, in an evolutionary sense, to the presence of microcystin-containing cyanobacteria in the diet (Hairston 1999; Sarnelle and Wilson 2005). Thus, it also seems prudent to be more circumspect about the source of the zooplankton strains used in laboratory studies of cyanobacteria-zooplankton interactions, if the goal is to understand these interactions in nature. Few of the studies in our meta-analysis provided detailed information about the habitat from which the zooplankton strains investigated were isolated. Given that prolonged exposure to the selective pressures of the laboratory-culture environment may lead to population evolution (Lynch et al. 1991), serious attention should also be paid to the interval between isolation from nature and use in experiments for both phytoplankton and zooplankton strains.

Cyanobacteria-zooplankton interactions can significantly influence planktonic community dynamics following nutrient and fish manipulations (Sommer 1989). With this in mind, understanding the mechanisms mediating these interactions is critical to effective water quality management. Furthermore, our quantitative survey of the cyanobacteria-zooplankton literature highlights a further need for experiments aimed at teasing apart the effects of cyanobacterial morphology, toxicity, nutrient deficiencies, and interactions among these mechanisms on zooplankton fitness. Finally, copepods are an important link in aquatic food webs (Sommer 1989), and numerous studies have demonstrated the effects of blue-green algae on copepod filtration rate, egg production, and survival (DeMott et al. 1991). Surprisingly, we found only one article that compared individual fitness data for copepods fed a mixture of a cyanobacterium of unknown toxicity and a chlorophyte with fitness data for copepods fed a unialgal diet of the green alga (Twombly et al. 1998). In this study, the cyanobacterial diet was not shown to affect individual grazer fitness. Thus, we encourage future studies aimed at evaluating the effect of cyanobacteria on copepod fitness.

\section{References}

ArNold, D. E. 1971. Ingestion, assimilation, survival, and reproduction by Daphnia pulex fed seven species of bluegreen algae. Limnol. Oceanog. 16: 906-920.

BuRNS, C. W. 1987. Insights into zooplankton-cyanobacteria interactions derived from enclosure studies. N. Z. J. Mar. Freshw. Res. 21: 477-482.

Caldwell, G. S., S. B. Watson, and M. G. Bentley. 2004. How to assess toxin ingestion and post-ingestion partitioning in zooplankton? J. Plankton Res. 26: 1369-1377.

Carmichael, W. W. 1992. Cyanobacteria secondary metabolites - the cyanotoxins. J. Appl. Bacteriol. 72: 445-459.

, S. Azevedo, J. S. An, R. J. R. Molica, E. M. Jochimsen, S. Lau, K. L. Rinehart, G. R. Shaw, and G. K. Eaglesham. 2001. Human fatalities from cyanobacteria: Chemical and biological evidence for cyanotoxins. Environ. Health Perspect. 109: 663-668.

Chan, F., M. L. Pace, R. W. Howarth, and R. M. Marino. 2004. Bloom formation in heterocystic nitrogen-fixing cyanobacteria: The dependence on colony size and zooplankton grazing. Limnol. Oceanog. 49: 2171-2178.

Chorus, I., And J. Bartram [eds.]. 1999. Toxic cyanobacteria in water: A guide to their public health consequences, monitoring and management. E \& FN Spon.

DeMott, W. R. 1989. The role of competition in zooplankton succession, p. 195-252. In U. Sommer [ed.], Plankton ecology: Succession in plankton communities. Springer-Verlag.

—, Q. X. Zhangand W. W. Carmichael. 1991. Effects of toxic cyanobacteria and purified toxins on the survival and feeding of a copepod and three species of Daphnia. Limnol. Oceanog. 36: 1346-1357.

Englund, G., O. Sarnelle, and S. D. Cooper. 1999. The importance of data-selection criteria: Meta-analyses of stream predation experiments. Ecology 80: 1132-1141.

Ferrão-Filho, A. S., ANd S. Azevedo. 2003. Effects of unicellular and colonial forms of toxic Microcystis aeruginosa from laboratory cultures and natural populations on tropical cladocerans. Aquat. Ecol. 37: 23-35.

Fulton, R. S., And H. W. Paerl. 1987. Effects of colonial morphology on zooplankton utilization of algal resources during blue-green algal (Microcystis aeruginosa) blooms. Limnol. Oceanog. 32: 634-644.

Gilbert, J. J. 1990. Differential effects of Anabaena affinis on cladocerans and rotifers: Mechanisms and implications. Ecology 71: 1727-1740.

. 1994. Susceptibility of planktonic rotifers to a toxic strain of Anabaena flos-aquae. Limnol. Oceanog. 39: 1286-1297.

Gliwicz, Z. M. 1990. Daphnia growth at different concentrations of blue-green filaments. Archiv für Hydrobiologie 120: $51-65$. 
, AND E. Siedlar. 1980. Food size limitation and algae interfering with food collection in Daphnia. Archiv für Hydrobiologie 88: 155-177.

Gurevitch, J., and L. V. Hedges. 1999. Statistical issues in ecological meta-analyses. Ecology 80: 1142-1149.

Hairston, N. G., C. L. Holtmeier, W. Lampert, L. J. Weider, D. M. Post, J. M. Fischer, C. E. Cáceres, J. A. Fox, and U. GAEDKE. 2001. Natural selection for grazer resistance to toxic cyanobacteria: Evolution of phenotypic plasticity? Evolution 55: $2203-2214$.

Hartmann, H. J. 1985. Feeding of Daphnia pulicaria and Diaptomus ashlandi on mixtures of unicellular and filamentous algae. Verh. Int. Verein. Limnol. 22: 3178-3183.

Hurlbert, S. H. 1984. Pseudoreplication and the design of ecological field experiments. Ecol. Monogr. 54: 187-211.

Jeppesen, E., J. P. Jensen, M. Søndergaard, T. Lauridsen, and F. LANDKILDEHUS. 2000. Trophic structure, species richness and biodiversity in Danish lakes: changes along a phosphorus gradient. Freshw. Biol. 45: 201-218.

Jungmann, D. 1992. Toxic compounds isolated from Microcystis PCC7806 that are more active against Daphnia than two microcystins. Limnol. Oceanog. 37: 1777-1783.

Kaebernick, M., T. Rohrlack, K. Christoffersen, and B. A. NeILAN. 2001. A spontaneous mutant of microcystin biosynthesis: Genetic characterization and effect on Daphnia. Environ. Microbiol. 3: 669-679.

KomÁrek, J. 1991. A review of water-bloom forming Microcystis species, with regard to populations from Japan. Algological Stud. 64: 115-127.

LAMPERT, W. 1981. Toxicity of the blue-green Microcystis aeruginosa: Effective defence mechanism against grazing pressure by Daphnia. Verh. Int. Verein. Limnol. 21: 14361440.

- 1982. Further studies on the inhibitory effect of the toxic blue-green Microcystis aeruginosa on the filtering rate of zooplankton. Archiv für Hydrobiologie 94: 207-220.

1987. Laboratory studies on zooplankton-cyanobacteria interactions. N. Z. J. Mar. Freshw. Res. 21: 483-490.

LARsSON, P., AND S. Dodson. 1993. Chemical communication in planktonic animals. Archiv für Hydrobiologie 129: 129-155.

Lee, S. J., M. H. JANG, H. S. Kim, B. D. Yoon, and H. M. OH. 2000. Variation of microcystin content of Microcystis aeruginosa relative to medium $\mathrm{N}: \mathrm{P}$ ratio and growth stage. J. Appl. Microbiol. 89: 323-329.

LundstedT, L., AND M. T. BRETT. 1991. Differential growth rates of three cladoceran species in response to mono- and mixedalgal cultures. Limnol. Oceanog. 36: 159-165.

LÜRLING, M. 2003. Daphnia growth on microcystin-producing and microcystin-free Microcystis aeruginosa in different mixtures with the green alga Scenedemsus obliquus. Limnol. Oceanog. 48: 2214-2220.

Lynch, M. 1980. Aphanizomenon blooms: Alternate control and cultivation of Daphnia pulex, p. 299-304. In W. C. Kerfoot [ed.], The evolution and ecology of zooplankton communities. University Press of New England.

, W. Gabriel, AND A. M. Wood. 1991. Adaptive and demographic responses of plankton populations to environmental change. Limnol. Oceanog. 36: 1301-1312.

Moore, P. A., D. A. Fields, And J. Yen. 1999. Physical constraints of chemoreception in foraging copepods. Limnol. Oceanog. 44: 166-177.

NANDini, S., AND T. R. RaO. 1998. Somatic and population growth in selected cladoceran and rotifer species offered the cyanobacterium Microcystis aeruginosa as food. Aquat. Ecol. 31: 283-298.
Osenberg, C. W., O. Sarnelle, S. D. Cooper, and R. D. Holt. 1999. Resolving ecological questions through meta-analysis: Goals, metrics, and models. Ecology 80: 1105-1117.

Plath, K. 1998. Adaptive feeding behavior of Daphnia magna in response to short-term starvation. Limnol. Oceanog. 43: 593-599.

Porter, K. G., And R. McDonough. 1984. The energetic cost of response to blue-green algal filaments by cladocerans. Limnol. Oceanog. 29: 365-369.

— AND J. D. ORcutT. 1980. Nutritional adequacy, manageability, and toxicity as factors that determine the food quality of green and blue-green algae for Daphnia, p. 268-281. In W. C. Kerfoot [ed.], Evolution and ecology of zooplankton communities. University Press of New England.

Riemann, B., P. Simonsen, and L. Stensgatrd. 1989. The carbon and chlorophyll content of phytoplankton from various nutrient regimes. J. Plankton Res. 11: 1037-1045.

Robillot, C., J. Vinh, S. Puiseux-Dao, and M. C. Hennion. 2000. Hepatotoxin production kinetics of the cyanobacterium Microcystis aeruginosa PCC 7820, as determined by HPLCmass spectrometry and protein phosphatase bioassay. Environ. Sci. Technol. 34: 3372-3378.

Rohrlack, T., E. Dittmann, T. Börner, and K. Christoffersen. 2001. Effects of cell-bound microcystins on survival and feeding of Daphnia spp. Appl. Environ. Microbiol. 67: 3523-3529.

—, - M. Henning, T. Börner, And J. G. Kohl. 1999. Role of microcystins in poisoning and food ingestion inhibition of Daphnia galeata caused by the cyanobacterium Microcystis aeruginosa. Appl. Environ. Microbiol. 65: 737-739.

Rosenberg, M. S., D. C. Adams, and J. Gurevitch. 2002. METAWIN version 2.1: Statistical software for metaanalysis. Sinauer.

SARnelle, O., AND A. E. Wilson. 2005. Local adaptation of Daphnia pulicaria to toxic cyanobacteria. Limnol. Oceanog. 50: 1565-1570.

Smith, A. D., AND J. J. Gilbert. 1995. Relative susceptibilities of rotifers and cladocerans to Microcystis aeruginosa. Archiv für Hydrobiologie 132: 309-336.

SNell, T. W. 1998. Chemical ecology of rotifers. Hydrobiologia 388: $267-276$.

Sommer, U. 1989. Plankton ecology. Springer-Verlag.

Sterner, R. W. 1989. Resource competition during seasonal succession toward dominance by cyanobacteria. Ecology 70: 229-245.

Twombly, S., N. Clancy, and C. W. Burns. 1998. Life history consequences of food quality in the freshwater copepod Boeckella triarticulata. Ecology 79: 1711-1724.

von Elert, E., D. Martin-Creuzburg, and J. R. Le Coz. 2003. Absence of sterols constrains carbon transfer between cyanobacteria and a freshwater herbivore (Daphnia galeata). Proc. R. Soc. Lon. B 270: 1209-1214.

, AND T. Wolffrom. 2001. Supplementation of cyanobacterial food with polyunsaturated fatty acids does not improve growth of Daphnia. Limnol. Oceanog. 46: 1552-1558.

Webster, K. E., and R. H. Peters. 1978. Some size-dependent inhibitions of larger cladoceran filterers in filamentous suspensions. Limnol. Oceanog. 23: 1238-1245.

Wolfe, G. V. 2000. The chemical defense ecology of marine unicellular plankton: Constraints, mechanisms, and impacts. Biol. Bull. 198: 225-244.

Received: 19 November 2005 Accepted: 6 March 2006 Amended: 6 March 2006 


\title{
Effects of cyanobacterial toxicity and morphology on the population growth of freshwater zooplankton: Meta-analyses of laboratory experiments
}

\author{
Alan E. Wilson, Orlando Sarnelle and Angeline R. Tillmanns
}

\section{Web Appendix 1}

Table A1. List of studies used in the primary meta-analysis comparing $r$ for grazers fed control foods comprising chlorophytes and/ or flagellates and treatment foods containing cyanobacteria. Grazer types: $\mathrm{cl}=$ cladoceran $\left(\right.$ genera $={ }^{1}$ Bosmina, ${ }^{2}$ Ceriodaphnia, ${ }^{3}$ Chydoris, ${ }^{4}$ Daphnia, ${ }^{5}$ Moina, ${ }^{6}$ Moinadaphnia, ${ }^{7}$ Scapholeberis, ${ }^{8}$ Simocephalus); and $\mathrm{r}=$ rotifer (genera $={ }^{9}$ Asplanchna, ${ }^{10}$ Brachionus, ${ }^{11}$ Hexarthra, ${ }^{12}$ Keratella, ${ }^{13}$ Synchaeta). Toxins analyzed and found to be present: ${ }^{14}$ anatoxin, ${ }^{15}$ deazaadenosine, ${ }^{16}$ glucopyranoside, ${ }^{17}$ microcystin. Morphology types: colonial $=$ colonial $[$ genera $=18$ Microcystis], filament $=$ filamentous $[$ genera $=19$ Anabaena, ${ }^{20}$ Aphanizomenon, ${ }^{21}$ Cylindrospermopsis, ${ }^{22}$ OscillatorialPlanktothrix], and single $=$ single-celled $\left(\right.$ genera $={ }^{19}$ Anabaena, ${ }^{23}$ Anacystis, ${ }^{24}$ Gleocapsa, ${ }^{25}$ Merismopedia, ${ }^{18}$ Microcystis, ${ }^{26}$ Synechococcus, ${ }^{27}$ Synechocystis). ND $=$ toxin presence not determined by chemical analysis. * Studies employing toxic Microcystis PCC7820.

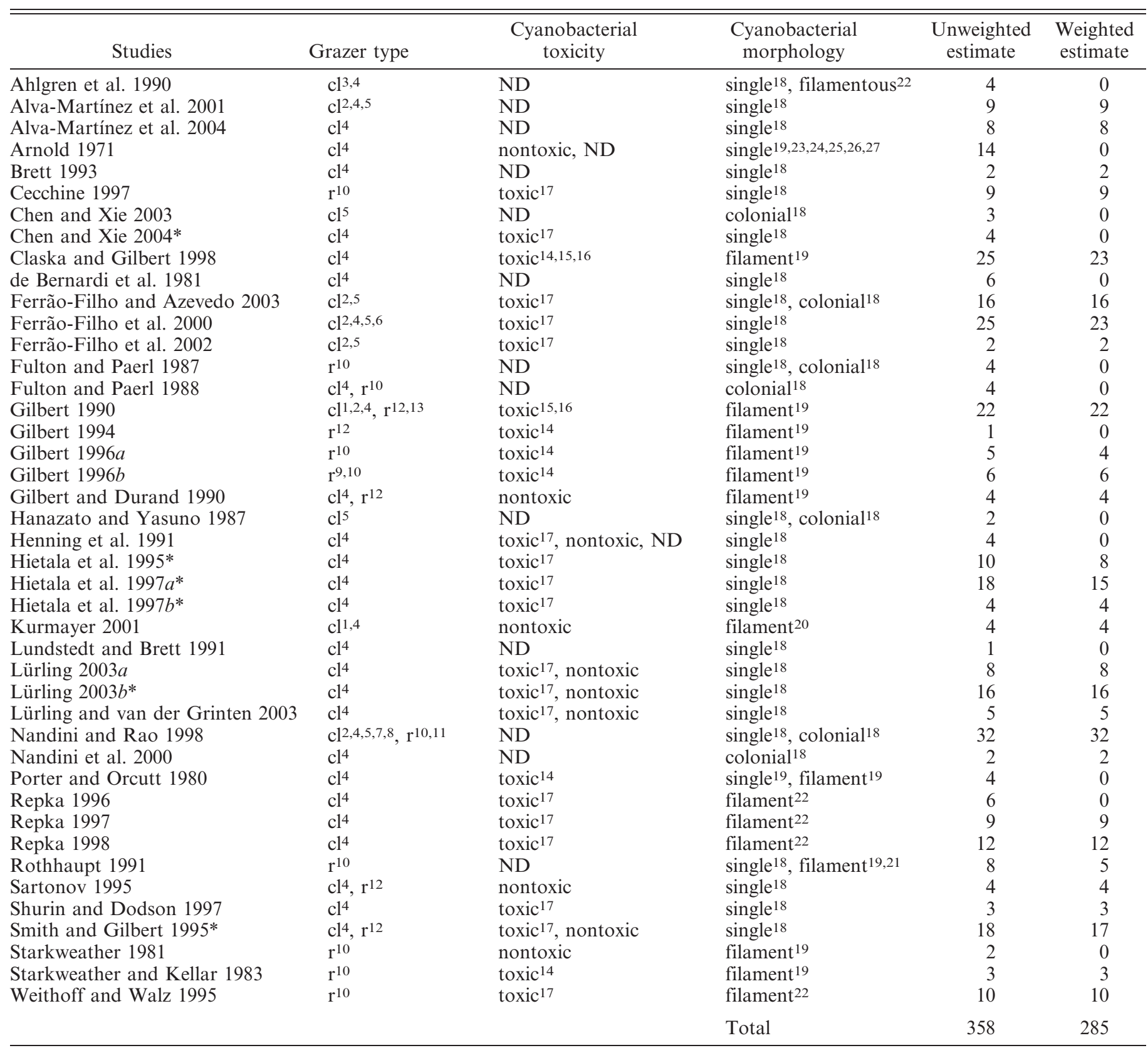


Table A2. List of studies used in the secondary meta-analysis comparing $r$ derived from survivorship curves, LT $_{50}$ estimates, or directly from papers for grazers fed treatment foods containing cyanobacteria and no food. Data types: survivor $=$ survivorship curves, $\mathrm{LT}_{50}=\mathrm{LT}_{50}$ estimates, and $r=r$ provided in or calculated from paper. Grazer types: ana $=$ anostracan [Genus $=1$ Thamnocephalus], cl $=$ cladoceran [Genera $={ }^{2}$ Bosmina, ${ }^{3}$ Ceriodaphnia, ${ }^{4}$ Daphnia, ${ }^{5}$ Moina,${ }^{6}$ Moinadaphnia], cop $=$ copepod $\left[\right.$ Genera $={ }^{7}$ Cyclops,${ }^{8}$ Diaptomus, ${ }^{9}$ Eudiaptomus], and $\mathrm{r}=$ rotifer [Genus $={ }^{10}$ Brachionus]. Toxins analyzed and found to be present: ${ }^{11}$ anatoxin, ${ }^{12}$ cylindrospermopsin, ${ }^{13}$ deazaadenosine, ${ }^{14}$ glucopyranoside, ${ }^{15}$ microcystin, ${ }^{16}$ microviridin, ${ }^{17}$ paralytic shellfish toxin]. Morphology types: filament $=$ filamentous $\left[\right.$ Genera $={ }^{18}$ Anabaena, ${ }^{19}$ Aphanizomenon, ${ }^{20}$ Cylindrospermopsis $]$, and single $=$ single-celled $\left[\right.$ Genera $={ }^{18}$ Anabaena, ${ }^{21}$ Microcystis, ${ }^{22}$ Planktothrix]. ND $=$ toxin presence not-determined by chemical analysis. ${ }^{*}=$ studies employing toxic Microcystis PCC7820.

\begin{tabular}{|c|c|c|c|c|c|}
\hline Studies & Data type & Grazer types & $\begin{array}{c}\text { Cyanobacterial } \\
\text { toxicity }\end{array}$ & $\begin{array}{c}\text { Cyanobacterial } \\
\text { morphology }\end{array}$ & $\begin{array}{c}\text { Treatment } \\
\text { food - no food }\end{array}$ \\
\hline Cecchine 1997 & $r$ & $\mathrm{r}^{10}$ & toxic 15 & $\operatorname{single}^{21}$ & 1 \\
\hline DeMott et al. $1991^{*}$ & survivor & $\mathrm{cl}^{4}, \operatorname{cop}^{8}$ & toxic $^{15}$, nontoxic & single 21 & 12 \\
\hline Ferrão-Filho et al. 2000* & survivor & $\mathrm{cl}^{3,4,5,6}$ & toxic 15 & single 21 & 97 \\
\hline Fulton $1988^{*}$ & survivor & $\mathrm{cl}^{2,4,5}$ & toxic $^{11,15}$ & single $^{21}$, filament ${ }^{18}$ & 8 \\
\hline Gilbert 1998 & survivor & $\mathrm{cl}^{4}$ & $\operatorname{toxic}^{13,14}$ & filament 18 & 2 \\
\hline Henning et al. 1991 & $r$ & $\mathrm{cl}^{4}$ & toxic 15 , nontoxic & single 21 & 2 \\
\hline Henning et al. 2001 & survivor & $\mathrm{cl}^{4}$ & toxic 15 , nontoxic & single 21 & 5 \\
\hline Kaebernick et al. 2001 & survivor & $\mathrm{cl}^{4}$ & toxic 15 , nontoxic & single 21 & 4 \\
\hline Kurmayer and Jüttner 1999 & survivor & ana $^{1}, \mathrm{cl}^{4}, \operatorname{cop}^{7,9}$ & toxic $^{15}$ & single 22 & 4 \\
\hline Lürling $2003 a$ & $r$ & $\mathrm{cl}^{4}$ & toxic ${ }^{15}$, nontoxic & single 21 & 8 \\
\hline Matveev et al. 1994 & survivor & $\mathrm{cl}^{4}$ & toxic 15 & single 21 & 1 \\
\hline Nizan et al. $1986^{*}$ & survivor & $\mathrm{cl}^{4}$ & toxic 15 & single 21 & 4 \\
\hline Nogueira et al. $2004 a$ & survivor & $\mathrm{cl}^{4}$ & $\operatorname{toxic}^{17}$ & filament 19 & 1 \\
\hline Nogueira et al. $2004 b$ & survivor & $\mathrm{cl}^{4}$ & toxic $^{12}$, nontoxic & filament 20 & 2 \\
\hline Porter and Orcutt 1980 & $r$ & $\mathrm{cl}^{4}$ & toxic 11 & single $^{18}$, filament 18 & 4 \\
\hline Reinikainen et al. $1994^{*}$ & survivor & $\mathrm{cl}^{4}$ & toxic $^{15}$ & single 21 & 48 \\
\hline Rohrlack et al. $1999 a$ & survivor & $\mathrm{cl}^{4}$ & toxic 15 , nontoxic & single 21 & 2 \\
\hline Rohrlack et al. $1999 b$ & $\mathrm{LT}_{50}$ & $\mathrm{cl}^{4}$ & toxic 15 , nontoxic & single 21 & 6 \\
\hline Rohrlack et al. 2001 & $\mathrm{LT}_{50}$ & $\mathrm{cl}^{4}$ & toxic 15 , nontoxic & single 21 & 12 \\
\hline Rohrlack et al. 2004 & survivor & $\mathrm{cl}^{4}$ & toxic 16 & single 21 & 2 \\
\hline Smith and Gilbert 1995 & $r$ & $\mathrm{cl}^{4}$ & nontoxic & single 21 & 1 \\
\hline \multirow{3}{*}{$\begin{array}{l}\text { Thostrup and Christoffersen } 1999 \\
\text { van der Grinten et al. } 2000\end{array}$} & survivor & $\mathrm{cl}^{4}$ & toxic $^{15}$ & single 21 & 1 \\
\hline & survivor & $\mathrm{cl}^{4}$ & toxic ${ }^{15}$, nontoxic & single 21 & 12 \\
\hline & & & & Total & 239 \\
\hline
\end{tabular}


Table A3. Grazer genera included in the primary and secondary meta-analyses comparing $r$ for grazers fed control foods comprised of chlorophytes and/or flagellates and treatment diets containing cyanobacteria.

\begin{tabular}{|c|c|c|c|c|}
\hline Meta-analysis & Genera & Grazer group & No. species & $\begin{array}{l}\text { Unweighted effect } \\
\text { size estimates }\end{array}$ \\
\hline Primary & Asplanchna & rotifer & 1 & 3 \\
\hline Primary & Bosmina & cladoceran & 1 & 3 \\
\hline Primary & Ceriodaphnia & cladoceran & 2 & 34 \\
\hline Primary & Chydoris & cladoceran & 1 & 2 \\
\hline Primary & Daphnia & cladoceran & 10 & 200 \\
\hline Primary & Moina & cladoceran & 2 & 27 \\
\hline Primary & Moinadaphnia & cladoceran & 1 & 6 \\
\hline Primary & Scapholeberis & cladoceran & 1 & 4 \\
\hline Primary & Simocephalus & cladoceran & 1 & 4 \\
\hline Primary & Synchaeta & rotifer & 1 & 2 \\
\hline Primary & & Total & 27 & 358 \\
\hline Secondary & Cyclops & copepod & 1 & 1 \\
\hline Secondary & Daphnia & cladoceran & 8 & 164 \\
\hline Secondary & Diaptomus & copepod & 1 & 4 \\
\hline Secondary & Eudiaptomus & copepod & 1 & 1 \\
\hline Secondary & Moina & cladoceran & 1 & 21 \\
\hline Secondary & Moinadaphnia & cladoceran & 1 & 28 \\
\hline Secondary & Thamnocephalus & anostracan & 1 & 1 \\
\hline Secondary & & Total & 17 & 239 \\
\hline
\end{tabular}

Table A4. List of excluded comparisons not used in the primary and secondary meta-analyses.

\begin{tabular}{llcc}
\hline \hline Meta-analysis & \multicolumn{1}{c}{ Study } & Comparisons excluded & Reason for exclusion \\
\hline Primary & Ahlgren et al. 1990 & 2 & control $r$ near or below 0 \\
Primary & Chen and Xie 2003 & 9 & control $r$ near or below 0 \\
Primary & Ferrão-Filho et al. 2000 & 4 & unable to calculate treatment $r$ \\
Primary & Laurén-Määttä et al. 1997 & 4 & control $r$ near or below 0 \\
Primary & Lundstedt and Brett 1991 & 2 & control near or below 0 \\
Primary & Weithoff and Walz 1995 or below 0 \\
Primary & Total & 1 & starvation $r$ above 0 \\
Secondary & Arnold 1971 & 22 & 14 \\
Secondary & Total & 14 & \\
\hline
\end{tabular}




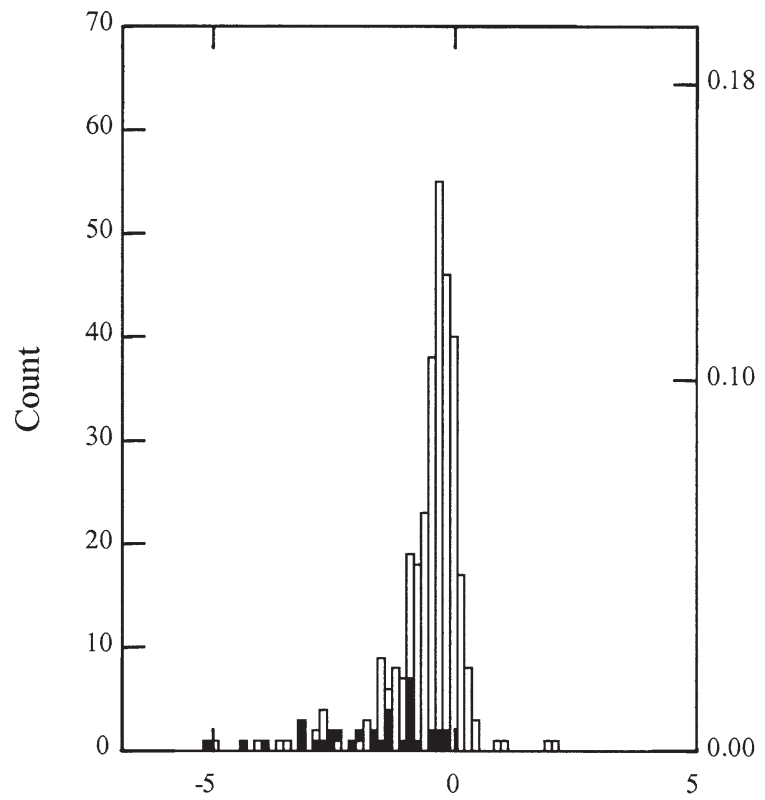

Unweighted effect size

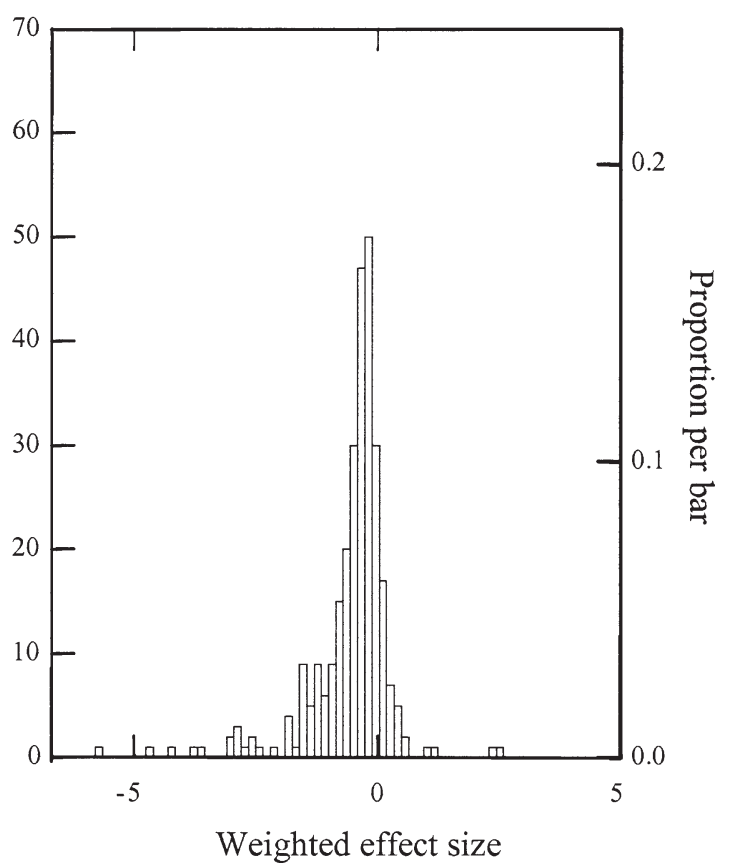

Figure A1. Frequency distribution of effect sizes for unweighted and weighted estimates of $r$ comparisons for grazers fed control foods composed of chlorophytes and/or flagellates and treatment foods containing cyanobacteria used in the primary meta-analysis. Most effect sizes were calculated by using $r$ estimates collected directly from the studies (white bars); however, a few $r$ estimates were calculated from survivorship data (black bars).

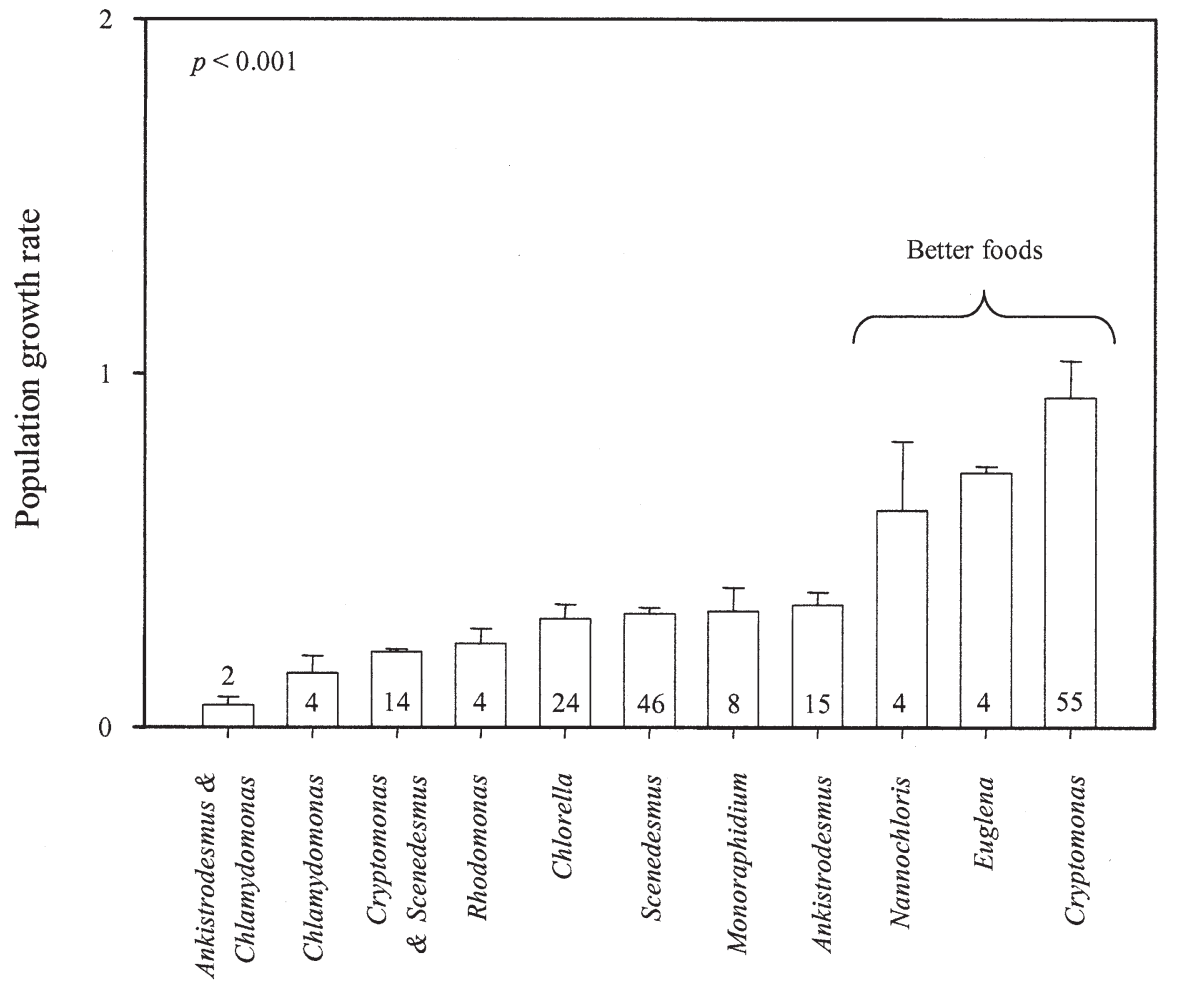

Control foods

Figure A2. Control food population growth rates (mean $\pm 1 \mathrm{SE}$ ) for grazers used in the primary meta-analysis. Inset numbers indicate sample size for each estimate where each control food growth rate estimate was used only once per study, even if multiple effect size estimates incorporated the same control food growth rate estimate more than once. 


\section{References}

Ahlgren, G., L. Lundstedt, M. Brett, and C. Forsberg. 1990. Lipid composition and food quality of some freshwater phytoplankton for cladoceran zooplankters. J. Plankton Res. 12: $809-818$.

Alva-Martínez, A. F., S. S. S. Sarma, and S. Nandini. 2001. Comparative population dynamics of three species of cladocera in relation to different levels of Chlorella vulgaris and Microcystis aeruginosa. Crustaceana 74: 749-764.

- 2004. Population growth of Daphnia pulex (Cladocera) on a mixed diet (Microcystis aeruginosa with Chlorella or Scenedesmus). Crustaceana 77: 973-988.

Arnold, D. E. 1971. Ingestion, assimilation, survival, and reproduction by Daphnia pulex fed seven species of bluegreen algae. Limnol. Oceanogr. 16: 906-920.

Brett, M. T. 1993. Resource quality effects on Daphnia longispina offspring fitness. J. Plankton Res. 15: 403-412.

Cecchine, G. A. 1997. Combinations of natural and anthropogenic stressors affect populations of freshwater rotifers. Georgia Institute of Technology.

Chen, F. Z., And P. XIE. 2003. The effects of fresh and decomposed Microcystis aeruginosa on cladocerans from a subtropic Chinese Lake. J. Freshw. Ecol. 18: 97-104.

- 2004. The toxicities of single-celled Microcystis aeruginosa PCC7820 and liberated M. aeruginosa to Daphnia carinata in the absence and presence of the green alga Scenedesmus obliquus. J. Freshw. Ecol. 19: 539-545.

Claska, M. E., and J. J. Gilbert. 1998. The effect of temperature on the response of Daphnia to toxic cyanobacteria. Freshw. Biol. 39: 221-232.

de Bernardi, R., G. Diussani, and E. L. Pedretti. 1981. The significance of blue-green algae as food for filter feeding zooplankton: Experimental studies of Daphnia spp. fed Microcystis aeruginosa. Verh. Int. Verein. Limnol. 21: 477483.

DeMott, W. R., Q. X. Zhang, and W. W. Carmichael. 1991. Effects of toxic cyanobacteria and purified toxins on the survival and feeding of a copepod and three species of Daphnia. Limnol. Oceanogr. 36: 1346-1357.

Ferrão-Filho, A. S., S. Azevedo, and W. R. DeMott. 2000. Effects of toxic and nontoxic cyanobacteria on the life history of tropical and temperate cladocerans. Freshw. Biol. 45: $1-19$.

Ferrão-Filho, A. S., P. Domingos, and S. Azevedo. 2002. Influences of a Microcystis aeruginosa Kutzing bloom on zooplankton populations in Jacarepagua Lagoon (Rio de Janeiro, Brazil). Limnologica 32: 295-308.

Ferrão-Filho, A. S., ANd S. Azevedo. 2003. Effects of unicellular and colonial forms of toxic Microcystis aeruginosa from laboratory cultures and natural populations on tropical cladocerans. Aquat. Ecol. 37: 23-35.

Fulton, R. S. 1988. Resistance to blue-green algal toxins by Bosmina longirostris. J. Plankton Res. 10: 771-778.

Fulton, R. S., And H. W. Paerl. 1987. Toxic and inhibitory effects of the blue-green alga Microcystis aeruginosa on herbivorous zooplankton. J. Plankton Res. 9: 837-855.

- 1988. Effects of the blue-green alga Microcystis aeruginosa on zooplankton competitive abilities. Oceologia 76: 383-389.

Gilbert, J. J. 1990. Differential effects of Anabaena affinis on cladocerans and rotifers: Mechanisms and implications. Ecology 71: 1727-1740.

-. 1994. Susceptibility of planktonic rotifers to a toxic strain of Anabaena flos-aquae. Limnol. Oceanogr. 39: $1286-1297$. 1996a. Effect of food availability on the response of planktonic rotifers to a toxic strain of the cyanobacterium Anabaena flos-aquae. Limnol. Oceanogr. 41: 1565-1572.

1996b. Effect of temperature on the response of planktonic rotifers to a toxic cyanobacterium. Ecology 77: 1174-1180.

1998. Differential sensitivity of Synchaeta and Daphnia to nucleosides from Anabaena affinis. Hydrobiologia 388: 277-281.

Gilbert, J. J., AND M. W. Durand. 1990. Effect of Anabaena flosaquae on the abilities of Daphnia and Keratella to feed and reproduce on unicellular algae. Freshw. Biol. 24: 577-596.

Hanazato, T., and M. Yasuno. 1987. Evaluation of Microcystis as food for zooplankton in a eutrophic lake. Hydrobiologia 144: $251-259$.

Henning, M., H. Hertel, H. Wall, and J. G. Kohl. 1991. Strainspecific influence of Microcystis aeruginosa on food ingestion and assimilation of some cladocerans and copepods. Int. Rev. Gesamten Hydrobiol. 76: 37-45.

Henning, M., T. Rohrlack, And J. G. Kohl. 2001. Responses of Daphnia galeata fed with Microcystis strains with and without microcystins, p. 266-280. In I. Chorus [ed.], Cyanotoxins. Springer.

Hietala, J., C. Laurén-MäÄttä, And M. Walls. 1997a. Life history responses of Daphnia clones to toxic Microcystis at different food levels. J. Plankton Res. 19: 917-926. - 1997b. Sensitivity of Daphnia to toxic cyanobacteria: Effects of genotype and temperature. Freshw. Biol. 37: 299-306.

Hietala, J., M. Reinikainen, and M. Walls. 1995. Variation in life history responses of Daphnia to toxic Microcystis aeruginosa. J. Plankton Res. 17: 2307-2318.

Kaebernick, M., T. Rohrlack, K. Christoffersen, and B. A. NeIlan. 2001. A spontaneous mutant of microcystin biosynthesis: Genetic characterization and effect on Daphnia. Environ. Microbiol. 3: 669-679.

Kurmayer, R. 2001. Competitive ability of Daphnia under dominance of nontoxic filamentous cyanobacteria. Hydrobiologia 442: 279-289.

Kurmayer, R., AND F. JÜtTNER. 1999. Strategies for the coexistence of zooplankton with the toxic cyanobacterium Planktothrix rubescens in Lake Zurich. J. Plankton Res. 21: 659-683.

Laurén-MäÄttä, C., J. Hietala, and M. Walls. 1997. Responses of Daphnia pulex populations to toxic cyanobacteria. Freshw. Biol. 37: 635-647.

Lundstedt, L., And M. T. BRetT. 1991. Differential growth rates of three cladoceran species in response to mono- and mixedalgal cultures. Limnol. Oceanogr. 36: 159-165.

LÜRling, M. 2003a. Daphnia growth on microcystin-producing and microcystin-free Microcystis aeruginosa in different mixtures with the green alga Scenedemsus obliquus. Limnol. Oceanogr. 48: 2214-2220.

- 2003b. Effects of microcystin-free and microcystin containing strains of the cyanobacterium Microcystis aeruginosa on growth of the grazer Daphnia magna. Environ. Toxicol. 18: 202-210.

LÜrling, M., AND E. VAn DER Grinten. 2003. Life-history characteristics of Daphnia exposed to dissolved microcystinLR and to the cyanobacterium Microcystis aeruginosa with and without microcystins. Environ. Toxicol. Chem. 22: 1281-1287.

Matveev, V., L. Matveeva, and G. L. Jones. 1994. Study of the ability of Daphnia carinata King to control phytoplankton 
and resist cyanobacterial toxicity: Implications for biomanipulation in Australia. Aust. J. Mar. Freshw. Res. 45: 889-904.

NANDini, S., AND T. R. RaO. 1998. Somatic and population growth in selected cladoceran and rotifer species offered the cyanobacterium Microcystis aeruginosa as food. Aqat. Ecol. 31: 283-298.

Nandini, S., S. S. S. Sarma, and P. Ramírez-García. 2000. Life table demography and population growth of Daphnia laevis (Cladocera, Anomopoda) under different densities of Chlorella vulgaris and Microcystis aeruginosa. Crustaceana 73: 1273-1286.

Nizan, S., C. Dimentman, And M. Shilo. 1986. Acute toxic effects of the cyanobacterium Microsystis aeruginosa on Daphnia magna. Limnol. Oceanogr. 31: 497-502.

Nogueira, I. C. G., P. Pereira, E. Dias, S. Pflugmacher, C. Wiegand, S. Franca, And V. M. Vasconcelos. 2004a. Accumulation of paralytic shellfish toxins (PST) from the cyanobacterium Aphanizomenon issatschenkoi by the cladoceran Daphnia magna. Toxicon 44: 773-780.

Nogueira, I. C. G., M. L. SAker, S. Pflugmacher, C. Wiegand, AND V. M. VAsconcelos. 2004b. Toxicity of the cyanobacterium Cylindrospermopsis raciborskii to Daphnia magna. Environ. Toxicol. 19: 453-459.

Porter, K. G., And J. D. Orcutt. 1980. Nutritional adequacy, manageability, and toxicity as factors that determine the food quality of green and blue-green algae for Daphnia, p. 268-281. In W. C. Kerfoot [ed.], Evolution and ecology of zooplankton communities. Univ. Press of New England.

Reinikainen, M., M. Ketola, and M. Walls. 1994. Effects of the concentration of toxic Microcystis aeruginosa and an alternative food on the survival of Daphnia pulex. Limnol. Oceanogr. 39: 424-432.

REPKA, S. 1996. Inter- and intraspecific differences in Daphnia life histories in response to two food sources: The green alga Scenedesmus and the filamentous cyanobacterium Oscillatoria. J. Plankton Res. 18: 1213-1223.

. 1997. Effects of food type on the life history of Daphnia clones from lakes differing in trophic state. I. Daphnia galeata feeding on Scenedesmus and Oscillatoria. Freshw. Biol. 38: $675-683$.

. 1998. Effects of food type on the life history of Daphnia clones from lakes differing in trophic state. II. Daphnia cucullata feeding on mixed diets. Freshw. Biol. 38: 685-692.

Rohrlack, T., K. Christoffersen, M. Kaebernick, and B. A. NeILAN. 2004. Cyanobacterial protease inhibitor microviridin
$\mathbf{J}$ causes a lethal molting disruption in Daphnia pulicaria. Appl. Environ. Microbiol. 70: 5047-5050.

Rohrlack, T., E. Dittmann, T. Börner, and K. Christoffersen. 2001. Effects of cell-bound microcystins on survival and feeding of Daphnia spp. Appl. Environ. Microbiol. 67: 3523-3529.

Rohrlack, T., E. Dittmann, M. Henning, T. Börner, and J. G. KoHL. 1999a. Role of microcystins in poisoning and food ingestion inhibition of Daphnia galeata caused by the cyanobacterium Microcystis aeruginosa. Appl. Environ. Microbiol. 65: 737-739.

Rohrlack, T., M. Henning, and J. Kohl. 1999b. Does the toxic effect of Microcystis aeruginosa on Daphnia galeata depend on microsystin ingestion rate? Arch. Hydrobiol. 146: 385-395.

Rothнaupt, K. O. 1991. The influence of toxic and filamentous blue-green algae on feeding and population growth of the rotifer, Brachionus rubens. Int. Rev. Gesamten Hydrobiol. 76: $67-72$.

Sartonov, A. 1995. Effects of Microcystis aeruginosa on interference competition between Daphnia pulex and Keratella cochlearis. Hydrobiologia 307: 117-126.

Shurin, J. B., AND S. I. Dodson. 1997. Sublethal toxic effects of cyanobacteria and nonylphenol on environmental sex determination and development in Daphnia. Environ. Toxicol. Chem. 16: 1269-1276.

Smith, A. D., And J. J. Gilbert. 1995. Relative susceptibilities of rotifers and cladocerans to Microcystis aeruginosa. Arch. Hydrobiol. 132: 309-336.

Starkweather, P. L. 1981. Trophic relationships between the rotifer Brachionus calyciflorus and the blue-green alga Anabaena flos-aquae. Verh. Int. Verein. Limnol. 21: 15071514.

Starkweather, P. L., and P. E. Kellar. 1983. Utilization of cyanobacteria by Brachionus calyciflorus: Anabaena flos-aquae (NRC-44-1) as a sole or complementary food source. Hydrobiologia 104: 373-377.

Thostrup, L., and K. Christoffersen. 1999. Accumulation of microcystin in Daphnia magna feeding on toxic Microcystis. Arch. Hydrobiol. 145: 447-467.

VAN Der Grinten, E., M. Lürling, and T. Burger-Wiersma. 2000. Is Microcystis really toxic to Daphnia? Verh. Int. Verein. Limnol. 27: 3226-3229.

Weithoff, G., and N. Walz. 1995. Influence of the filamentous cyanobacterium Planktothrix agardhii on population growth and reproductive pattern of the rotifer Brachionus calyciflorus. Hydrobiologia 313: 381-386. 